ет несколько масок, одной из которых является церебральная.

\section{ЛИТЕРАТУРА}

1. Цитко ЕВ, Малаева ЕГ, Мистюкевич ИИ, Цырульникова АН, Алейникова ТВ, Ходунов ОБ, Литовченко ЕЮ, Ярмоленко ОА. Инфекционный эндокардит: учебно-метод пособие для студ 5 и 6 курсов всех факультетов мед вузов, врачей общей практики, кардиологов и терапевтов. Гомель, РБ: ГомГМУ; 2016. 6 с.

2. Ватутин НТ, Тарадин ГГ, Чаус ЕА, Смирнова АС. Инфекционный эндокардит у пожилых: от этиологических особенностей до лечения и профилактики. Рос Кардиологический Журн. 2016;(1):80-89. doi: https://doi.org/10.15829/1560-4071-2016-1-80-89

3. Habib G, Lancellotti P, Antunes M, Bongiorni M, Casalta J, Zotti F, Dulgheru R, Khoury G, Erba P, Iung B, Miro J, Mulder B, Plonska-Gosciniak E, Price S, Roos-Hesselink J, Snygg-Martin U, Thuny F, Mas P, Vilacosta I, Zamorano J, Демин AA. Рекомендации ESC по ведению больных с инфекционным эндокардитом 2015. Рос Кардиологический Журн. 2016;(5):65-116. doi https://doi.org/10.15829/1560-4071-2016-5-65-116

4. Лобзин ЮВ, Левина АС. Клинические маски инфекционного эндокардита. Журн Инфектологии. 2015;7(2):14-20. doi: https://doi.org/10.22625/2072-6732-2015-7-2-14-20

5. Клинический протокол «Диагностика и лечение пациентов с заболеваниями нервной системы (взрослое население)». [Электронный ресурс]. Министерство здравоохранения Респ Беларусь. Постановление №8 18 янв 2018г; (158). [дата обращения: 2020 Февр 18]. Available from: http://minzdrav.gov.by/upload/ dadvfiles/КПневрология\%20(взрослые) амб.\%20и\%20стац.\%20y сл. пост.\%20МЗ\%20РБ\%20от\%2018.01.2018\%20№8.pdf

\section{REFERENCES}

1. Citko EV, Malaeva EG, Mistjukevich II, Cyrul'nikova AN, Alejnikova TV, Hodunov OB, Litovchenko EJu, Jarmolenko OA. Infekcionnyj jendokardit: uchebno-metod posobie dlja stud 5 i 6 kursov vseh fakul'tetov med vuzov, vrachej obshhej praktiki, kardiologov i terapevtov. Gomel', RB: GomGMU; 2016. 6 p. (in Russ.)

2. Vatutin NT, Taradin GG, Chaus EA, Smirnova AS. Infekcionnyj jendokardit u pozhilyh: ot jetiologicheskih osobennostej do lechenija i profilaktiki. Ros Kardiologicheskij Zhurn. 2016;(1):8089. doi: https://doi.org/10.15829/1560-4071-2016-1-80-89 (in Russ.)

3. Habib G, Lancellotti P, Antunes M, Bongiorni M, Casalta J, Zotti F, Dulgheru R, Khoury G, Erba P, Iung B, Miro J, Mulder B, Plonska-Gosciniak E, Price S, Roos-Hesselink J, Snygg-Martin U, Thuny F, Mas P, Vilacosta I, Zamorano J, Demin AA. Rekomendacii ESC po vedeniju bol'nyh s infekcionnym jendokarditom 2015. Ros Kardiologicheskij Zhurn. 2016;(5):65-116. doi: https://doi.org/10. 15829/1560-4071-2016-5-65-116 (in Russ.)

4.Lobzin JuV, Levina AS. Klinicheskie maski infekcionnogo jendokardita. Zhurn Infektologii. 2015;7(2):14-20. doi: https://doi. org/10.22625/2072-6732-2015-7-2-14-20 (in Russ.)

5. Klinicheskij protokol «Diagnostika i lechenie pacientov s zabolevanijami nervnoj sistemy (vzrosloe naselenie)». [Jelektronny] resurs]. Ministerstvo zdravoohranemija Resp Belarus'. Postanovlenie №8 18 janv 2018g; (158). [data obriashhenija: 2020 Fevr 18]. Available from: http://minzdrav.gov.by/upload/dadvfiles/ KP_nevrologija\% 20 (vzroslye) amb.\%20i\%20stac. $\% 20$ usl. post. $\% 20 \mathrm{MZ} \% 20 \mathrm{RB} \% 20$ o $\mathrm{t} \% 2018.01 .2018 \% 20 № 8 . p d f$ (in Russ.)

Адрес для корреспонденции 246000, Республика Беларусь, г. Гомель, ул. Ланге, 5 ,

УО «Гомельский государственный медицинский университет», кафедра внутренних болезней №1 с курсом эндокринологии,

Тел/факс: +375 232 53-85-08,

Тел. моб.:+375 445538957 ,

e-mail: alina.prislopskaya90@gmail.com

Прислопская Алина Юрьевна

Сведения об авторах

Прислопская А.Ю., ассистент кафедры внутренних болезней № 1 с курсом эндокринологии УО «Гомельский государственный медицинский университет».

https://orcid.org/0000-0002-3101-7820

Цырульникова А.Н., старший преподаватель кафедрь внутренних болезней №1 с курсом эндокринологии УО «Гомельский государственный медицинский университет».

https://orcid.org/0000-0003-41054-3934

Малаева Е.Г., к.м.н., доцент кафедры внутренних болезней №1 с курсом эндокринологии УО «Гомельский государственный медицинский университет».

https://orcid.org/0000-0003-1051-0787

Address for correspondence

5 Lange Street, 246000 ,

Gomel, Republic of Belarus,

Gomel State Medical University,

Department of Internal Medicine No.1 with the course of Endocrinology,

Tel./fax: +375 232 53-85-08,

Tel. mob.: +375445538957

e-mail: alina.prislopskaya90@gmail.com

Prislopskaya Alina Yuryevna

Information about authors

Prislopskaya A.Yu., assistant lecturer at the Department of Internal Medicine No.1 with the course of Endocrinology of the EI «Gomel State Medical University».

https://orcid org/0000-0002-3101-7820

Tsyrulnicova A.N., senior lecturer at the Department of Internal Medicine No.1 with the course of Endocrinology EI «Gomel State Medical University».

https://orcid.org/0000-0003-41054-3934

Malayeva E.G., Candidate of Medical Sciences, Associate Professor, Head of the Department of Internal Medicine No.1 with the course of Endocrinology EI «Gomell State Medical University». https://orcid.org/0000-0003-1051-0787

Поступила 14.02.2020

\title{
НОВЫЕ ТЕХНОЛОГИИ
}

\section{УДК 616.12-091-008.331.1 \\ СТРУКТУРНО-ФУНКЦИОНАЛЬНЫЕ ОСОБЕННОСТИ СЕРДЕЧНО-СОСУДИСТОЙ СИСТЕМЫ ПРИ АРТЕРИАЛЬНОЙ ГИПЕРТЕНЗИИ С НОРМАЛЬНЫМ СПЕКТРОМ ТРАНСМИТРАЛЬНОГО КРОВОТОКА}

\author{
Е. Ф. Семеняго ${ }^{1}$, Д. П. Саливончик ${ }^{2}$ \\ ${ }^{1}$ Государственное учреждение \\ «Республиканский научно-практический центр \\ радиационной медицины и экологии человека» \\ г. Гомель, Республика Беларусь \\ ${ }^{2}$ Учреждение образования \\ «Гомельский государственный медицинский университет» \\ г. Гомель, Республика Беларусь
}

Цель: оценить структурно-функциональные особенности сердечно-сосудистой системы у пациентов с артериальной гипертензией (АГ) и нормальным спектром трансмитрального кровотока (НСТК). 
Материалы и методы. Организовано открытое проспективное исследование в ГУ «РНПЦРМ и ЭЧ» пациентов с эссенциальной АГ $(\mathrm{n}=31)$ и здоровых добровольцев $(\mathrm{n}=10)$. Исследуемые лица сопоставимы по половозрастным признакам. Всем участникам исследования была выполнена трансторакальная эхокардиография (ЭхоКГ) с определением стандартных показателей, ультразвуковое исследование экстракраниального отдела брахиоцефальных артерий (БЦА) с определением толщины комплекса интима-медиа (КИМ) и каротидных бляшек, дуплексное сканирование артерий верхних и нижних конечностей с определением лодыжечноплечевого индекса (ЛПИ) и эндотелийзависимой вазодилатации (ЭЗВД). Дополнительно оценивались глобальная продольная деформация методом двухмерного отслеживания пятен серой шкалы ультразвукового изображения (speckle tracking), показатели движения фиброзного кольца атриовентрикулярных клапанов в систолу и диастолу с определением миокардиального индекса методом тканевой допплерографии (ТДГ).

Pезультаmы. У пациентов с АГ и НСТК по сравнению со здоровыми лицами были выявлены достоверные изменения переднезаднего размера (38 мм против 32,5 мм; $\mathrm{p}=0,001)$ и объема (45 мл против 31,5 мл; $\mathrm{p}=0,002)$ левого предсердия (ЛП) и объема $(37,5$ мл против 29,5 мл; $\mathrm{p}=0,005)$ правого предсердия (ПП), измеренных с помощью стандартной трансторакальной ЭхоКГ. При использовании метода двухмерного отслеживания пятен серой шкалы ультразвукового изображения в исследуемой группе по сравнению с контрольной регистрировались более низкие значения глобального продольного стрейна $(-17,5$ против $-21,6 ;$ p $<$ $0,001)$, что свидетельствует о нарушении биомеханики сокращения миокарда левого желудочка (ЛЖ). Исследование движения фиброзных колец атриовентрикулярных клапанов методом тканевой допплерографии (ТДГ) показало, что во второй группе пациентов имеют место регионарные нарушения диастолической функции, в первую очередь это касается медиальной части ФК МК $(1,3$ против 1,$1 ; \mathrm{p}=0,05)$ и латеральной части ФК ТК $(1,3$ против 0,$8 ; \mathrm{p}=0,028)$. Кроме того, по сравнению со здоровыми лицами регистрировались более высокие значения миокардиального индекса для латеральной $(0,51$ против 0,$43 ; p=0,001)$ и медиальной части $(0,59$ против 0,$44 ; \mathrm{p}=0,001)$ ФК МК, латеральной части $(0,58$ против 0,$44 ; \mathrm{p}=0,001)$ ФК ТК.

У пациентов исследуемой группы по сравнению с контрольной были выявлены признаки патологического ремоделирования сосудистой стенки. В первой группе исследуемых по сравнению со второй значение толщины комплекса интима-медиа (КИМ) было несколько выше (справа $p=0,061$, слева $p=0,08)$ и зарегистрированы случаи наличия атеросклеротических бляшек (АСБ).

Заключение. Протокольные методы исследования не позволяют в полной мере оценить функциональные особенности сердца у пациентов с АГ, что требует проведения дополнительных способов диагностики: ТДГ и speckle tracking.

Ключевые слова: артериальная гипертензия, трансмитральный кровоток, левое предсердие, глобальная продольная деформация, миокардиальный индекс.

Objective: to assess the structural and functional features of the cardiovascular system in patients with arterial hypertension $(\mathrm{AH})$ and normal spectrum of transmitral blood flow (NSTBF).

Material and methods. An open prospective study of patients with essential hypertension $(\mathrm{n}=31)$ and healthy volunteers $(n=10)$ was organized at the state institution «Republican Research Center for Radiation Medicine and Human Ecology». The examined individuals were comparable in terms of sex and age features. All the participants of the study underwent transthoracic echocardiography (EchoCG) with the determination of the standard parameters, ultrasound of the extracranial part of the brachiocephalic arteries (BCA) with the determination of the thickness of the intima-media complex (CIM) and carotid plaques, duplex scanning of the arteries of the upper and lower extremities with the measurement of the ankle-brachial index (LPI) and endothelium-dependent vasodilation (EDVD). In addition, we assessed the global longitudinal deformation by the method of two-dimensional speckle tracking of the gray spots of the ultrasound image, the indicators of the movement of the fibrous ring of the atrioventricular valves into systole and diastole with the determination of the myocardial index by tissue dopplerography (TDG).

Results. In comparison with the healthy volunteers, the patients with AH and NSTB have detected reliable changes in the anteroposterior size $(38 \mathrm{~mm}$ versus $32.5 \mathrm{~mm} ; \mathrm{p}=0.001)$ and volume $(45 \mathrm{ml}$ versus $31.5 \mathrm{ml} ; \mathrm{p}=$ $0.002)$ of the left atrium (LP) and volume $(37.5 \mathrm{ml}$ versus $29.5 \mathrm{ml}, \mathrm{p}=0.005)$ of the right atrium (PP), measured by means of standard transthoracic echocardiography. Using the method of two-dimensional tracking of the speckle spots of the gray scale of the ultrasound image we have recorded lower values of the global longitudinal strain (-17.5 versus $-21.6 ; \mathrm{p}<0.001)$ in the study group compared with the control group, which indicates a violation of the biomechanics of the myocardial contractions of the left ventricle (LV). The study of the movement of the fibrous rings of the atrioventricular valves using tissue dopplerography (TDG) has showed that in the second group of the patients there are regional disorders of diastolic function, primarily this concerns the medial part of FC MK (1.3 versus 1.1 ; $p=0.05)$ and the lateral part of FC TC $(1.3$ versus $0.8 ; p=0.028)$. In addition, in comparison with the healthy individuals we recorded higher values of the myocardial index for the lateral $(0.51$ versus $0.43 ; \mathrm{p}=0.001)$ and medial parts $(0.59$ versus $0.44 ; \mathrm{p}=0.001) \mathrm{FC} \mathrm{MK}$, lateral part $(0.58$ versus $0.44 ; \mathrm{p}=0.001) \mathrm{FC} \mathrm{TC}$.

The patients of the study group, in comparison with the control one, have revealed signs of the pathological remodeling of the vascular wall. In the first group of the examined individuals, in comparison with the second one, the thickness of the intima-media complex (CIM) was slightly higher $(p=0.061$ on the right, $p=0.08$ on the left) and cases of the presence of atherosclerotic plaques (ASB) were recorded.

Conclusion. The protocol research methods do not allow the comprehensive evaluation of the functional features of the heart in patients with $\mathrm{AH}$, which requires additional diagnostic methods: TDH and speckle tracking.

Key words: arterial hypertension, transmitral blood flow, left atrium, global longitudinal deformation, myocardial index.

E. F. Semeniago, D.P. Salivonchik

Structural and Functional Features of the Cardiovascular System in Arterial Hypertension with Normal Spectrum of Transmitral Blood Flow

Problemy Zdorov'ya i Ekologii. 2020 Jan-Mar; Vol 63 (1): 118-125 


\section{Введение}

АГ является одной из самых значимых медико-социальных проблем современности, так как достаточно часто встречается, является независимым фактором риска осложнений со стороны сердечно-сосудистой системы и одной из причин преждевременной смертности [1].

Согласно последним данным эпидемиологических исследований, распространенность АГ среди взрослого населения составляет 44,9 \% [5]. Исследователи отмечают, что данная цифра неуклонно растет, за последние 20 лет частота встречаемости АГ выросла на 10-20\%, что связано с постарением населения, все большим распространением гиподинамии и ожирения $[1,5]$.

Повышенное артериальное давление (АД) стало причиной преждевременной смерти примерно в 10 миллионах случаев, и это несмотря на значительные достижения в диагностике и лечении АГ [1].

АГ способствует возникновению структурно-функциональных изменений сердечнососудистой системы. Гипертрофия миокарда левого желудочка (ГЛЖ) является главным проявлением структурных изменений со стороны сердца при АГ. Кроме структурной перестройки длительное и стойкое повышение АД способствует функциональному изменению миокарда, что проявляется диастолической дисфункцией ЛЖ (ДД ЛЖ). ДД ЛЖ может формироваться параллельно с ГЛЖ либо возникать при ее отсутствии, однако зачастую функциональные нарушения ЛЖ появляются раньше, чем увеличивается масса миокарда, что связано с фиброзом миокарда $[2,15]$. Ремоделирование сосудистого русла также является неотьемлемой частью АГ. Оно осуществляется в два этапа: функциональный и морфологический [4]. Первый этап включает функциональные изменения, которые проявляются дисфункцией эндотелия (ДЭ). Прогрессирование ДЭ приводит к увеличению сосудистого тонуса и формированию второго этапа: морфологических изменений в сосудистой стенке и способствует тромбообразованию. Второй этап представляет собой структурные изменения сосудистой стенки, которые возникают вследствие разрастания среднего слоя, и проявляется утолщением комплекса интима-медиа (КИМ) и формированием атеросклеротических бляшек.

Согласно национальным рекомендациям Республики Беларусь (РБ) по диагностике и лечению АГ, главным методом диагностики структурно-функциональных нарушений сердца является трансторакальная ЭхоКГ. Стандартный протокол ЭхоКГ-исследования предлагает оценивать состояние диастолической функции ЛЖ преимущественно по спектру трансмитрального кровотока [16]. Однако в настоящее время появились новые методики, такие как ТДГ и speckle tracking, которые позволяют детальнее и точнее оценить работу сердца и дать терапевту возможность адекватной терапии пациента с АГ.

\section{Цель исследования}

Оценить структурно-функциональные особенности сердечно-сосудистой системы у пациентов с АГ и НСТК.

\section{Материаль и методы}

Организовано открытое проспективное исследование в ГУ «РНПЦРМ и ЭЧ» пациентов с эссенциальной АГ (n= 31) и здоровых добровольцев $(\mathrm{n}=0)$. Средний возраст пациентов составил 40,8 $\pm 8,6$ года. Все включенные в исследование пациенты были разделены на две группы. Первую группу составили 10 здоровых участников исследования, во вторую группу вошел 31 пациент с АГ и НСТК (АГ 1-й степени 11 пациентов (35\%), АГ 2-й степени - 16 пациентов (52\%), АГ 3-й степени - 4 пациента (13\%). Длительность заболевания составляла около 5 лет. Группы пациентов сопоставимы по возрасту и полу, $\mathrm{p}>0,05$. Лечение пациентов с АГ по группам антигипертензивных препаратов сопоставимо, $\mathrm{p}>0,05$.

Критериями включения в исследование являлись: информированное согласие пациента на участие в исследовании, наличие эссенциальной АГ с НСТК.

Критериями исключения в исследовании были: эссенциальная АГ с признаками ДД ЛЖ, хроническая сердечная недостаточность (ХCH), фракция выброса (ФВ) ЛЖ $\leq 50$ \%, перенесенный инфаркт миокарда, нестабильная стенокардия, наличие гемодинамически значимых клапанных пороков сердца, симптоматическая АГ, наличие нарушений ритма, онкологические заболевания, тяжелая легочная, почечная и печеночная патология.

Диагностика и лечение АГ проводилась в соответствии с клиническим протоколом диагностики и лечения болезней, характеризующихся повышенным кровяным давлением (№ 59 от 06.06.2017 г.) и рекомендациями Европейского общества кардиологов по диагностике и лечению АГ (2018 г.) [1, 6].

Всем пациентам проводилось стандартное трансторакальное ЭхоКГ на фоне синусового ритма с помощью ультразвукового аппарата VIVID q (General Electric, USA) фазированным секторным датчиком 2-4 МГц в М-, В-, импульсно-волновом (PW), непрерывноволновом $(\mathrm{CW})$ и цветном допплеровском режимах по стандартной методике [7].

Для оценки систолической функции ЛЖ использовались такие показатели, как конечнодиастолический размер (КДР), конечносистолический размер (КСР), фракция укоро- 
чения (ФУ), определенные в М-режиме по уравнению Тейхольца, конечно-систолический (КСО) и конечно-диастолический (КДО) объемы ЛЖ, ударный объем (УО) ЛЖ, ФВ ЛЖ, измеренные в В-режиме, верхушечным биплановым методом дисков (модификация по Simpson). Систолическую функцию считали сохранной при $Ф \mathrm{~B} \geq 50 \%$ [12].

Диастолическая функция ЛЖ оценивалась по спектру трансмитрального кровотока, измеренного в импульсно-волновом режиме. Диастолическую функцию считали ненарушенной при соотношении скоростей трансмитрального кровотока в раннюю и позднюю диастолу $(\mathrm{E} / \mathrm{A})>1$, время замедления потока в раннюю диастолу (DT) $<220$ мс, время изоволюметрического расслабления (IVRT) $<100$ мс. Дополнительно определяли отношение интегралов скоростей в раннюю и позднюю диастолу (VTIE/VTIA) 2,8 $\pm 0,65$, скорость наполнения ЛЖ в раннюю диастолу $(\mathrm{Vp})>55 \mathrm{~cm} / \mathrm{c}$, измеренную в М-режиме [13]. Кроме того, для описания структурных особенностей сердца определялись переднезадний размер левого предсердия (ЛП), индексированное значение переднезаднего размера ЛП, толщина межжелудочковой перегородки (МЖП) и задней стенки (3С) в систолу и диастолу, индекс относительной толщины стенки ЛЖ (ОТС). Объем ЛП измерялся из апикальной 4-камерной позиции методом Симпсон. Масса миокарда и индекс массы миокарда рассчитывались в В-режиме методом «площадь-длина». Индексированные показатели рассчитывались путем деления полученных величин на площадь поверхности тела.

Скорость движения ФК МК исследовалась с помощью метода ТДГ в импульсноволновом режиме на ультразвуковом аппарате VIVID q (General Electric, USA) фазированным секторным датчиком 2-4 МГц по стандартной методике [11]. Определялись следующие показатели: систолическая скорость движение ФК MК (Sm), скорость движения ФК МК в раннюю (Em) и позднюю (Am) диастолу, рассчитывали отношение скоростей движения ФК МК в раннюю и позднюю диастолу (Em/Am), отношение скорости трансмитрального кровотока в раннюю диастолу к диастолическому движению ФК МК в раннюю диастолу (E/Em). Нормой считали $\mathrm{Sm}$ - от 8 до $18 \mathrm{~cm} / \mathrm{c}$, $\mathrm{Em} / \mathrm{Am}>1, \mathrm{Em}-9-16 \mathrm{~cm} / \mathrm{c}, \mathrm{Am}-9-16 \mathrm{~cm} / \mathrm{c}$, отношение $\mathrm{E} / \mathrm{Em}<8$ [11].

Глобальная продольная деформация определялась по спекл-трекинг технологии в программе AFI с помощью ультразвукового аппарата VIVID q (General Electric, USA) фазированным секторным датчиком 2-4 МГц по стандартной методике. Нормальным показателем глобального продольного стрейна считали значение $20 \pm 3 \%$ [8].
Миокардиальный индекс (Теі-индекс) определялся с помощью метода ТДГ по спектру движения ФК МК и ФК ТК и вычислялся по формуле: отношение суммы периодов IVRT и изоволюметрического расслабления (IVST) ко времени изгнания. Нормальным значением Теі-индекса считали $0,34 \pm 0,04$ с [10].

Дуплексное сканирование экстракраниального отдела БЦА проводилось с помощью ультразвукового аппарата экспертного класса VIVID q (General Electric, USA) линейным датчиком 5-7 МГц в стандартных позициях по стандартному протоколу с использование В-, М-режима, импульсно-волнового допплера и цветного допплеровского картирования [9].

Измерение толщины КИМ осуществлялось на $1-1,5$ см проксимальнее бифуркации общей сонной артерии (OCA) по задней стенке в месте максимального утолщения. КИМ $>0,9$ мм считали патологическим. О наличии атеросклеротической бляшки судили в случае локального утолщения КИМ от 1,5 мм и более либо локального выпячивания сосудистой стенки на 0,5 мм или на $50 \%$ и более по сравнению с толщиной КИМ на соседних участках. Процент стенозирования рассчитывался по диаметру (площади) поперечного сечения $[1,9]$.

Оценка ЭЗВД осуществлялась с помощью манжеточной пробы. Проводили дуплексное сканирование плечевой артерии (ПА) по методике D. Celermajer на ультразвуковом аппарате VIVID q (General Electric, USA) с помощью линейного датчика 5-7 МГц. ЭЗВД рассчитывали по отношению изменения диаметра ПА после 5-минутной окклюзии сосуда пневматической манжетой к исходному в диастолу, выраженному в процентах. Увеличение диаметра на $10 \%$ и выше от исходного значения считали нормальной реакцией сосуда на окклюзию [9].

Оценка ЛПИ проводилась с помощью ультразвукового аппарата VIVID q (General Electric, USA) линейным датчиком 5-7 МГц. С помощью импульсноволнового допплера определялось систолическое артериальное давление (САД) на ПА и заднебольшеберцовой артерии (ЗББА). ЛПИ рассчитывали, как отношение САД на ЗББА и САД на ПА. Нормальным значением ЛПИ считали $0,9-1,2[9,14]$.

Статистический анализ данных проводили при помощи статистического пакета SPSS 15,0. Для сравнения групп между собой использовались методы непараметрической статистики. Результаты представлены в виде Ме (25\%; $75 \%)$. Сравнение количественных показателей проводилось с помощью теста Манна-Уитни. Различия считали статистически значимыми при $\mathrm{p}<0,05$.

\section{Результаты и обсуждение}

Данные ультразвукового исследования сердца у здоровых лиц и пациентов с АГ и НСТК представлены в таблице 1. 
Таблица 1 - Показатели ЭхоКГ в исследуемых группах

\begin{tabular}{|c|c|c|c|}
\hline Показатель & $\begin{array}{c}\text { 1-я группа } \\
\text { (здоровые лица, } \mathrm{n}=10 \text { ) }\end{array}$ & $\begin{array}{c}\text { 2-я группа } \\
(\mathrm{A} \Gamma \mathrm{c} \mathrm{HCTK,} \mathrm{n}=31)\end{array}$ & \begin{tabular}{|c|} 
Достоверность различия \\
между группами, $\mathrm{p}$
\end{tabular} \\
\hline Объем ЛП, мл & $31,5(29,3 ; 40,3)$ & $45(36 ; 52)$ & $\mathrm{p}=0,002^{*}$ \\
\hline Индексированный объем ЛП, мл $/ \mathrm{M}^{2}$ & $17,4(15,2 ; 20,5)$ & $22(19 ; 25)$ & $\mathrm{p}=0,007^{*}$ \\
\hline Переднезадний размер ЛП, мм & $32,5(29 ; 34,5)$ & $38(36 ; 40)$ & $\mathrm{p}=0,001^{*}$ \\
\hline $\begin{array}{l}\text { Индексированный переднезадний } \\
\text { размер ЛП, мм/м² }\end{array}$ & $16,8(15,7 ; 18,1)$ & $18,7(17,4 ; 20)$ & $\mathrm{p}=0,004^{*}$ \\
\hline КДОЛЖ в М-режиме, мл & $118,5(104,8 ; 129,8)$ & $127(110 ; 147)$ & $p=0,316$ \\
\hline КДОЛЖ в В-режиме, мл & $67(62,8 ; 71)$ & $70(58 ; 82,8)$ & $p=0,57$ \\
\hline КДРЛЖ, мм & $50(47,5 ; 52)$ & $53(48 ; 55)$ & $p=0,2$ \\
\hline МЖП в диастолу, мм & $9(8 ; 9,3)$ & $9(8 ; 10)$ & $p=0,9$ \\
\hline ЗСЛЖ в диастолу, мм & $9(8 ; 9)$ & $9(8 ; 9)$ & $p=0,7$ \\
\hline OTC & $0,34(0,33 ; 0,35)$ & $0,33(0,3 ; 0,38)$ & $p=0,7$ \\
\hline Масса миокарда ЛЖ, г & $98,5(91,5 ; 112,5)$ & $117(99 ; 130)$ & $\mathrm{p}=0,07$ \\
\hline Индекс массы миокарда ЛЖ, г/м² & $53,5(46,1 ; 58,8)$ & $58(50 ; 63)$ & $p=0,18$ \\
\hline Объем ПП, мл & $29,5(24,8 ; 32,3)$ & $37,5(30 ; 44,8)$ & $\mathrm{p}=0,005^{*}$ \\
\hline Индексированный объем ПП, мл/м² & $15(12,9 ; 17,8)$ & $17,5(14,9 ; 21,1)$ & $\mathrm{p}=0,037^{*}$ \\
\hline IVR MK, мс & $74(60,5 ; 80)$ & $75(67 ; 89)$ & $\mathrm{p}=0,3$ \\
\hline DT MK, мс & $207(188 ; 226)$ & $185(173 ; 209)$ & $\mathrm{p}=0,1$ \\
\hline $\mathrm{Vp}, \mathrm{cm} / \mathrm{c}$ & $62(52 ; 71)$ & $54(48 ; 65)$ & $\mathrm{p}=0,16$ \\
\hline VTIE/VTIA MK & $1,87(1,78 ; 1,98)$ & $1,9(1,7 ; 2,2)$ & $p=0,56$ \\
\hline
\end{tabular}

Примечания: НСТК - нормальный спектр трансмитрального кровотока, ДДЛЖ - диастолическая дисфункция ЛЖ, АГ - артериальная гипертензия, ЛП - левое предсердие, КДОЛЖ - конечнодиастолический объем левого желудочка, КДРЛЖ — конечно-диастолический размер ЛЖ, МЖП - межжелудочковая перегородка, ЗСЛЖ - задняя стенка левого желудочка, ОТС - относительная толщина стенок, ПП - правое предсердие, ЛЖ - левый желудочек, MК - митральный клапан, IVR - время изоволюметрического расслабления, DT - время замедления потока в раннюю диастолу, Vp - скорость наполнения ЛЖ в раннюю диастолу, VTIE - интеграл линейной скорости кровотока в раннюю диастолу, VTIA — интеграл линейной скорости кровотока в позднюю диастолу, $\mathrm{n}$ - число исследуемых в группах.

* — Достоверные различия между группами $(\mathrm{p}<0,05)$

Результаты, приведенные в таблице 1, свидетельствуют о том, что у пациентов с АГ и НСТК по сравнению со здоровыми лицами регистрировались более высокие значения переднезаднего размера (38 мм против 32,5 мм, $\mathrm{p}=0,001)$ и объема (45 мл против 31,5 мл, $\mathrm{p}=$ $0,002)$ ЛП и объема $(37,5$ мл против 29,5 мл, $\mathrm{p}=0,005)$ ПП. Вероятно, это связано с особен- ностью строения миокарда предсердий, который не способен компенсаторно гипертрофироваться, в отличие от миокарда желудочков, и в ответ на длительное повышение АД происходит их расширение.

Результаты ТДГ здоровых участников исследования и пациентов с АГ и НСТК представлены в таблице 2 .

Таблица 2 - Показатели тканевой допплерографии в исследуемых группах

\begin{tabular}{|l|c|c|c|}
\hline \multicolumn{1}{|c|}{ Показатель } & $\begin{array}{c}\text { 1-я группа } \\
\text { (здоровые лица, } \mathrm{n}=10)\end{array}$ & $\begin{array}{c}\text { 2-я группа } \\
\text { (АГ с НСТК, } \mathrm{n}=31)\end{array}$ & $\begin{array}{c}\text { Достоверность различия } \\
\text { между группами, } \mathrm{p}\end{array}$ \\
\hline Sm лФК МК, см/с & $0,12(0,12 ; 0,15)$ & $0,12(0,1 ; 0,14)$ & $\mathrm{p}=0,19$ \\
\hline Еm/Аm лФК МК & $1,4(1,3 ; 1,5)$ & $1,4(0,88 ; 1,7)$ & $\mathrm{p}=0,9$ \\
\hline $\mathrm{Sm} \mathrm{мФК} \mathrm{МК,} \mathrm{см/c}$ & $0,1(0,08 ; 0,1)$ & $0,9(0,08 ; 0,1)$ & $\mathrm{p}=0,43$ \\
\hline Еm/Аm мФК MК & $1,3(1,19 ; 1,4)$ & $1,1(0,8 ; 1,4)$ & $\mathrm{p}=0,05^{*}$ \\
\hline Sm мФК МК, см/c & $0,15(0,13 ; 0,17)$ & $0,14(0,13 ; 0,16)$ & $\mathrm{p}=0,7$ \\
\hline Еm/Аm лФК ТК & $1,3(1,18 ; 1,35)$ & $0,8(0,67 ; 1,3)$ & $\mathrm{p}=0,028^{*}$ \\
\hline Е/Елат & $5,45(4,6 ; 6,6)$ & $5,5(4,4 ; 6,7)$ & $\mathrm{p}=0,8$ \\
\hline Е/Емед & $6,3(5,5 ; 6,7)$ & $7(6 ; 9)$ & $\mathrm{p}=0,045^{*}$ \\
\hline Е/Еср & $5,9(5,1 ; 6,9)$ & $6,3(5,5 ; 7,7)$ & $\mathrm{p}=0,15$ \\
\hline
\end{tabular}

Примечания: НСТК - нормальный спектр трансмитрального кровотока, $\mathrm{Sm}$ - скорость движения фиброзного кольца в систолу, лФК - латеральная часть фиброзного кольца, Ет - скорость движения фиброзного кольца в раннюю диастолу, Am - скорость движения фиброзного кольца в позднюю диастолу, мФК - медиальная часть фиброзного кольца, ТК - трикуспидальный клапан, Е - скорость трансмитрального кровотока в раннюю диастолу, Елат - скорость движения латеральной части ФК МК в раннюю диастолу, Емед - скорость движения латеральной части ФК МК в позднюю диастолу, Еср - среднее значение.

* — Достоверные различия между группами $(\mathrm{p}<0,05)$ 
Исследование движения фиброзных колец атриовентрикулярных клапанов показало, что во второй группе пациентов имеют место регионарные нарушения диастолической функции, в первую очередь это касается медиальной части ФК МК $(\mathrm{p}=0,05)$ и латеральной части ФК ТК $(\mathrm{p}=0,028)$. Известно, что E/Em (Em скорость движения миокарда в раннюю диастолу, измеренная методом ТДГ) - показатель, характеризующий конечное диастолическое давление (КДД) в ЛЖ. Данный показатель в обеих группах составил менее 8 , что свидетельствует о том, что КДД ЛЖ не повышено, однако имеется статистически значимое различие между исследуемыми группами по дан- ному показателю для медиальной части ФК MK $(\mathrm{p}=0,045)$.

Результаты исследования миокардиального индекса представлены в таблице 3. Выявлено, что в группе здоровых респондентов значение Теі-индекса было ниже, чем в группе пациентов с АГ и НСТК $(\mathrm{p}<0,05)$. Известно, что миокардиальный индекс характеризует систолическую и диастолическую функцию миокарда желудочков одновременно. Следовательно, можно предположить, что у пациентов с АГ и нормальным спектром трансмитрального кровотока и сохранной фракцией выброса имеет место систолическая и диастолическая дисфункция.

Таблица 3 - Медиана значений Теі-индекса в исследуемых группах

\begin{tabular}{|l|c|c|c|}
\hline \multicolumn{1}{|c|}{ Теі-индекс } & $\begin{array}{c}\text { 1-я группа } \\
\text { (здоровые лица, } \mathrm{n}=10)\end{array}$ & $\begin{array}{c}\text { 2-я группа } \\
(\text { АГ без ДДЛЖ, } \mathrm{n}=31)\end{array}$ & $\begin{array}{c}\text { Достоверность различия } \\
\text { между группами, } \mathrm{p}\end{array}$ \\
\hline Латеральной части ФК МК & $0,43(0,41 ; 0,48)$ & $0,51(0,46 ; 0,56)$ & $\mathrm{p}=0,001^{*}$ \\
\hline Медиальной части ФК МК & $0,44(0,42 ; 0,48)$ & $0,59(0,53 ; 0,78)$ & $\mathrm{p}=0,001^{*}$ \\
\hline Латеральной части ФК ТК & $0,44(0,42 ; 0,45)$ & $0,58(0,49 ; 0,67)$ & $\mathrm{p}=0,001^{*}$ \\
\hline
\end{tabular}

Исследование продольной деформации миокарда ЛЖ показало, что медиана глобального продольного стрейна в первой группе исследуемых респондентов - $-21,6$ (-22,5 \%; $20,95 \%)$, во второй группе - -17,5 (-19,3\%; $-14,8 \%$ ) (таблица 4). Установлено, что во второй группе по сравнению с первой значение глобального продольного стрейна достоверно ниже $(\mathrm{p}<0,001)$. Вероятно, это связано с тем, что длительное стойкое повышение АД, приводит к метаболическим нарушениям в миокарде, возникает дефицит энергии, так как для нормальной работы миокарда в условиях повышенного АД необходимо в 4 раза больше кислорода, и как следствие, возникает нарушение биомеханики сокращения миокарда ЛЖ.

Таблица $4-$ Показатель глобального продольного стрейна в исследуемых группах

\begin{tabular}{|l|c|c|}
\hline \multicolumn{1}{|c|}{ Группы } & Глобальный продольный стрейн, \% & $\begin{array}{c}\text { Достоверность различия } \\
\text { между группами, } \mathrm{p}\end{array}$ \\
\hline 1-я группа (здоровые лица, $\mathrm{n}=10)$ & $-21,6(-22,5 ;-20,95)$ & $\mathrm{p}<0,001 *$ \\
\hline 2 2-я группа (АГ с НСТК, $\mathrm{n}=31)$ & $-17,5(-19,3 ;-14,8)$ & \\
\hline
\end{tabular}

* — Достоверные различия между группами $(\mathrm{p}<0,05)$

Показатели, характеризующие атеросклеротическое поражение БЦА представлены в таблице 5. У исследуемых первой и второй группы толщина КИМ не превышала нормальных значений. Установлено, что во второй группе в сравнении с первой толщина КИМ незначительно выше, однако различия между двумя группами статистически незначимы $(\mathrm{p}=$ 0,061). Несмотря на нормальное значение КИМ, в ряде случаев бляшки сформировались.

Таблица 5 - Сравнительная характеристика поражения БЦА

\begin{tabular}{|l|c|c|c|}
\hline \multicolumn{1}{|c|}{ Показатель } & $\begin{array}{c}\text { 1-я группа } \\
\text { (здоровые лица, } \mathrm{n}=10)\end{array}$ & $\begin{array}{c}\text { 2-я группа } \\
(\text { АГ с НСТК, } \mathrm{n}=31)\end{array}$ & $\begin{array}{c}\text { Достоверность различия } \\
\text { между группами, } \mathrm{p}\end{array}$ \\
\hline КИМ справа, мм & $0,6(0,5 ; 0,7)$ & $0,6(0,6 ; 0,7)$ & $\mathrm{p}=0,061$ \\
\hline КИМ слева, мм & $0,6(0,5 ; 0,7)$ & $0,7(0,6 ; 0,7)$ & $\mathrm{p}=0,08$ \\
\hline Каротидные бляшки справа, \% & 0 & $9(29)$ & \\
\hline Каротидные бляшки слева, \% & 0 & $7(22,5)$ & \\
\hline
\end{tabular}

Примечание: КИМ - комплекс интима-медиа 
Результаты исследования функции эндотелия показаны в таблице 6 . Полученные результаты свидетельствуют о большей величине ЭЗВД у здоровых лиц по сравнению с пациентами с АГ, но статистически значимых разли- чий между ними не обнаружено $(\mathrm{p}=0,14)$. В первой группе у всех исследуемых функция эндотелия была сохранена, среди пациентов второй группы выявлено 6 (19\%) случаев дисфункции эндотелия.

Таблица 6 - Показатели ЭЗВД в исследуемых группах

\begin{tabular}{|l|c|c|}
\hline \multicolumn{1}{|c|}{ Группы } & ЭЗВД, $\%$ & $\begin{array}{c}\text { Достоверность различия } \\
\text { между группами, } \mathrm{p}\end{array}$ \\
\cline { 1 - 2 } 1-я группа (здоровые лица, $\mathrm{n}=10)$ & $17,5(14,3 ; 24,3)$ & $\mathrm{p}=0,14$ \\
\hline 2-я группа (АГ с НСТК, $\mathrm{n}=31)$ & $14(10 ; 20)$ & \\
\hline
\end{tabular}

Примечание: ЭЗВД - эндотелийзависимая вазодилатация

Данные исследования субклинического поражения артерий нижних конечностей представлены в таблице 7. В первой и во второй группе исследуемых ЛПИ был в пределах нормальных значений. Различия групп между собой статистически незначимы ( $>>0,05)$.

Таблица 7 - Показатели ЛПИ в исследуемых группах

\begin{tabular}{|l|c|c|c|}
\hline \multicolumn{1}{|c|}{ ЛПИ } & $\begin{array}{c}1 \text {-я группа } \\
\text { (здоровые лица, } \mathrm{n}=10)\end{array}$ & $\begin{array}{c}\text { 2-я группа } \\
(\text { АГ без ДДЛЖ, } \mathrm{n}=31)\end{array}$ & $\begin{array}{c}\text { Достоверность различия } \\
\text { между группами, } \mathrm{p}\end{array}$ \\
\hline Справа & $1,08(1,0 ; 1,09)$ & $1,07(1,01 ; 1,08)$ & $\mathrm{p}=0,8$ \\
\hline Слева & $1,06(1,0 ; 1,09)$ & $1,07(1,05 ; 1,1)$ & $\mathrm{p}=0,3$ \\
\hline
\end{tabular}

Примечание: ЛПИ - лодыжечно-плечевой индекс

\section{Заключение}

Таким образом, у пациентов с АГ и НСТК по сравнению со здоровыми лицами были выявлены достоверные изменения переднезаднего размера (38 мм против 32,5 мм; $p=0,001)$ и объема (45 мл против 31,5 мл; $p=0,002$ ) левого предсердия (ЛП) и объема (37,5 мл против $29,5$ мл; $\mathrm{p}=0,005)$ правого предсердия (ПП), измеренных с помощью стандартной трансторакальной ЭхоКГ. При использовании метода двухмерного отслеживания пятен серой шкалы ультразвукового изображения в исследуемой группе по сравнению с контрольной регистрировались более низкие значения глобального продольного стрейна $(-17,5$ против $-21,6 ; \mathrm{p}<0,001)$, что свидетельствует о нарушении биомеханики сокращения миокарда левого желудочка (ЛЖ). Исследование движения фиброзных колец атриовентрикулярных клапанов методом тканевой допплерографии (ТДГ) показало, что во второй группе пациентов имеют место регионарные нарушения диастолической функции, в первую очередь это касается медиальной части ФК МК $(1,3$ против 1,$1 ; p=0,05)$ и латеральной части ФК ТК $(1,3$ против 0,$8 ; \mathrm{p}=$ $0,028)$. Кроме того, по сравнению со здоровыми лицами регистрировались более высокие значения миокардиального индекса для латеральной $(0,51$ против 0,$43 ; \mathrm{p}=0,001)$ и медиальной части $(0,59$ против 0,$44 ; \mathrm{p}=0,001)$ ФК МК, латеральной части $(0,58$ против 0,$44 ; \mathrm{p}=0,001)$ ФК ТК.
У пациентов исследуемой группы по сравнению с контрольной были выявлены признаки патологического ремоделирования сосудистой стенки. В первой группе исследуемых по сравнению со второй значение толщины комплекса интима-медиа (КИМ) было несколько выше (справа $p=0,061$, слева $p=0,08)$ и зарегистрированы случаи наличия атеросклеротических бляшек (АСБ).

Протокольные методы исследования не позволяют в полной мере оценить функциональные особенности сердца у пациентов с АГ, что требует проведения дополнительных способов диагностики: ТДГ и speckle tracking.

\section{ЛИТЕРАТУРА}

1. 2018 ЕОК/ЕОАГ рекомендации по лечению больных с артериальной гипертензией. Рос Кардиологический Журн. 2018;12(23):143-228.

2. Кузнецова ВВ, Бурсикова АВ. Диастолическая функция левого желудочка в дебюте выявления гипертонической болезни в молодом возрасте. Артериальная Гипертензия. 2007;4:292-94.

3. Алейникова ТВ. Ремоделирование сердца у пациентов, страдающих артериальной гипертензией. Проблемь Здоровья $u$ Экологии. 2009;2:55-60.

4. Назарова ОА, Назаров АВ. Поражение сосудов при артериальной гипертензии. Вестн Ивановской Мед Академии. 2012;2:60-66.

5. Распространенность факторов риска неинфекционных заболеваний в Республике Беларусь STEPS 2016. Минск, РБ: Европейское региональное бюро ВОЗ, 2017, 250 с.

6 . Клинический протокол диагностики и лечения болезней, характеризующихся повышенным кровяным давлением. Минск, РБ: МЗ Республики Беларусь 06.06. 2017 № 59, 174 с.

7. Рыбакова МК, Алехин МН, Митьков ВВ. Эхокардиография. Практ руководство по ультразвуковой диагностике. Москва, РФ: Издательский дом Видар-М; 2008, 512 с. 
8. Алехин МН. Ультразвуковые методы оценки деформации миокарда и их клиническое значение. Москва, РФ: Издательский дом Видар-М; 2012. 88 с.

9. Куликов ВП, Доронина НЛ, Шульгина ЛЭ, Дическул МЛ, Беспалов АГ, Федюнина НГ, Засорин СВ, Тимошевская НВ Ультразвуковая диагностика сосудистых заболеваний. Москва, РФ: ООО Фирма «СТРОМ»; 2007. 512 с.

10. Алехин МН, Барт БЯ, Ларина ВН, Барт ЮВ. Миокардиальный индекс обшей дисфункции сердца (Теі-индекс), возможности и ограничения. Ультразвуковая Диагностика. 2007;1:119-25.

11. Алехин МН. Тканевой допплер в клинической эхокардиографии. Москва, РФ: ООО «Инсвязьиздат»; 2006. 104 с.

12. Рекомендации ESC по диагностике и лечению острой и хронической сердечной недостаточности 2016. Рос Кард Журн. 2017;1(141):7-81.

13. Курлянская ЕК. Диастолическая сердечная недостаточность. Кардиология в Беларуси. 2009;4:37-50.

14. Бреговский ВБ. Лодыжечно-плечевой индекс как метод оценки субклинического поражения органов-мишеней при артериальной гипертензии. Артериальная Гипертензия. 2007;4(13):295-96.

15. Смакотина СА, Зверева ТН, Барбараш ОЛ. Ранние признаки поражения сердца при гипертонической болезни. Роль субклинического воспаления. Медииина в Кузбассе. 2009;4;32-36.

16. Мрочек АГ, Нечесова ТА, Коробко ИЮ, Ливенцева ММ, Павлова ОС, Пристром АМ. Диагностика, лечение и профилактика артериальной гипертензии. Национальные рекомендации. Минск, Беларусь: ГУ «Республиканский научно-практический центр «Кардиология» МЗ РБ; 2010. 53 с.

\section{REFERENCES}

1. $2018 \mathrm{ESC} / \mathrm{ESH}$ Guidelines for the management of arterial hypertension. Ros Kardiologicheskij Zhurn. 2018;12(23):143-228. (in Russ.)

2. Kuznetsova VV, Bursikova AV. Diastolic function left ventricle in a debut of revealing of hypertonic illness at young age. Arterial'naya Gipertenziya. 2007;4:292-94. (in Russ.)

3. Aleynikova TV. Heart remodeling at the patients, suffering from arterial hypertension. Problemy Zdorov'ya $i$ Ekologii. 2009;2:55-60. (in Russ.)

4. Nazarova OA, Nazarov AV. Vascular lesion in arterial hypertension Vestn Ivanovskoy Med Akademii. 2012;2:60-66. (in Russ.)

5 . Prevalence of risk factors for non-communicable diseases in Belarus STEPS 2016. Minsk, RB: Evropeyskoe regional'noe byuro VOZ, 2017, 250 p. (in Russ.)

6. Clinical protocol for diagnosis and treatment of diseases characterized by increased blood pressure. Minsk, RB: MZ Respubliki Belarus' 06.06. 2017 № 59, 174. (in Russ.)

7. Rybakova MK, Alekhin MN, Mit'kov VV. Echocardiography. Ultrasonic Diagnostic Practice Guide. Moskva, RF: Izdatel'skiy dom Vidar-M, 2008, 512 p. (in Russ.)

8. Alekhin MN. Ultrasonic methods of assessment of myocardial deformation and their clinical significance. Moskva, RF: Izdatel'skiy dom Vidar-M; 2012. 88 p. (in Russ.)

9. Kulikov VP, Doronina NL, Shul'gina LE, Dicheskul ML, Bespalov AG, Fedyunina NG, Zasorin SV, Timoshevskaya NV. U1trasonic diagnosis of vascular diseases. Moskva, RF: OOO Firma «STROM»; 2007. 512 p. (in Russ.)

10. Alekhin MN, Bart BYa, Larina VN, Bart YuV. Myocardial Performance Index of Global Cardiac Dysfunction (Tei-index), Potentialities and Limitations. Ul'trazvukovaya Diagnostika. 2007;1:119-25. (in Russ.)
11. Alekhin MN. Tissue doppler in clinical echocardiography. Moskva, RF: OOO «Insvyaz'izdat»; 2006. 104 p. (in Russ.)

12. 2016 ESC guidelines for the diagnosis and treatment of acute and chronic heart failure. Ross Kardiol Zhurnal. 2017;1(141):781. (in Russ.)

13. Kurlyanskaya EK. Diastolic heart failure. Kardiologiya $v$ Belarusi. 2009;4:37-50. (in Russ.)

14. Bregovskiy VB. Ankle-brachilal index as a method of assessment of subclinical target organ damage in hypertension. Arterial'naya Gipertenziya. 2007;4(13):295-96. (in Russ.)

15. Smakotina SA, Zvereva TN, Barbarash OL. Early signs of heart lesion in patients with arterial hypertension, the role of subclinical inflammation. Meditsina v Kuzbasse. 2009;4;32-36. (in Russ.)

16. Mrochek AG, Nechesova TA, Korobko IYu, Liventseva MM, Pavlova OS, Pristrom AM. Diagnosis, treatment and prevention of arterial hypertension. National recommendations. Minsk, Belarus': GU «Respublikanskiy nauchno-prakticheskiy tsentr «Kardiologiya» MZ RB; 2010. 53 p. (in Russ.)

Адрес для корреспонденции

246040, Республика Беларусь,

г. Гомель, ул. Ильича, 290,

ГУ «Республиканский научно-практический центр радиационной медицины и экологии человека»,

отделение функциональной диагностики,

Тел. моб.: +375296436356,

e-mail: eva.semenyago@mail.ru

Семеняго Евгения Федоровна

Сведения об авторах

Семеняго Е.Ф., врач отделения функциональной диагностики ГУ «Республиканский научно-практический центр радиационной медицины и экологии человека».

https://orcid.org/0000-0003-1094-8367

Саливончик Д.П., д.м.н., доцент, заведующий кафедрой внутренних болезней №3 с курсами лучевой диагностики, лучевой терапии, ФПКиП УО «Гомельский государственный медицинский университет».

https://orcid.org/0000-0001-8347-2166

Address for correspondence

290 Ilyicha Street, 246040

Gomel, Republic of Belarus

Republican Research Center for Radiation Medicine and $\mathrm{Hu}-$ man Ecology,

Department of Functional Diagnostics,

Mob.tel: +375296436356

e-mail: eva.semenyago@mail.ru

Semeniago Eugeniya Fiodorovna

Information about authors

Semeniago E.F., physician at the Department of Functional Diagnostics of the SI "Republican Research Center for Radiation Medicine and Human Ecology".

https://orcid.org/0000-0003-1094-8367

Salivonchik D.P., Doctor of Medical Sciences, Associate Professor at the Department of Internal Diseases No.3 with the courses of Radiation Diagnostics, Radiation Therapy, Faculty of Professional Development and Retraining of the EI "Gomel State Medical University".

https://orcid.org/0000-0001-8347-2166

Поступила 30.01.2020 